\title{
RANCANG BANGUN APLIKASI SISTEM INVENTORY (BAN) PADA GUDANG PT. GAJAH TUNGGAL Tbk. PLANT I
}

\author{
Nurlaila Suci Rahayu Rais ${ }^{1}$ \\ Moh. Fayumi ${ }^{2}$ \\ Ani Purwanita ${ }^{3}$ \\ Dosen STMIK Raharja ${ }^{1}$ \\ STMIK Raharja Jurusan Manajemen Informatika \\ STMIK Raharja Jurusan Sistem Informasi ${ }^{3}$ \\ Jl.Jendral Sudirman No.40 Cikokol Modern,Tangerang \\ e-mail:nurlaila@raharja.info, fayumi@raharja.info, ani.purwanita@raharja.info
}

\begin{abstract}
ABSTRAK
Saat ini perkembangan teknologi komputer sangat pesat dan telah menjadi kebutuhan utama dalam rangka meningkatkan kinerja suatu perusahaan. Keberadaan teknologi komputer sangat bermanfaat, karena setiap proses yang dilakukan secara manual dapat digantikan dengan menggunakan komputer, agar prosesnya dapat dilakukan dengan cepat dan pengerjaannya dapat lebih efisien. Permasalahan yang dihadapi oleh PT. Gajah Tunggal Tbk. adalah banyaknya stock barang (Ban) di gudang, khususnya Plant I yang memproduksi ban untuk keperluan assembling dan menyuplai kebutuhan produksi kendaraan bermotor pada pabrikan-pabrikan motor di Indonesia dan diluar negeri. Agar barang-barang tertata dengan baik, diperlukan sistem inventory (persediaan barang) yang diharapkan dapat mempermudah perusahaan dalam melakukan proses inventori secara terencana, terkontrol, sistematis dan mempercepat dalam proses mengambil suatu keputusan. Penelitian ini dilakukan melalui observasi langsung, wawancara, dan pengambilan data melalui dokumen tertulis, cetak maupun elektronik dari lembaga/institusi yang berkaitan dengan penelitian. Hasil analisa akan digunakan sebagai masukan dalam rancang bangun aplikasi sistem yang diusulkan. Perancangan aplikasi sistem ini menggunakan Rancangan sistem untuk menggambarkan Use Case Diagram, Activity Diagram, Class Diagram; Rancangan Prototype yang terdiri dari Rancangan Menu, Rancangan Entry/Input Data dan Rancangan Laporan. Hasil penelitian dengan adanya sistem yang tersusun dengan rapi diharapkan dapat mengontrol proses suatu kegiatan pada perusahaan, sehingga dapat mengurangi terjadinya penyimpangan-penyimpangan dan pekerjaan dapat terselesaikan dengan tepat waktu.
\end{abstract}

Kata kunci: Rancang Bangun, Aplikasi, Sistem Inventory.

\begin{abstract}
Nowadays, the development of computer technology is very rapidly and has become a major requirement in order to improve the performance of a company. The existence of computer technology is very beneficial, because each process that is performed manually can be replaced by using a computer, so that the process can be done quickly and efficiently. The problem faced by PT. Gajah Tunggal Tbk. is the large quantities of stock items (tires) in storage, especially Plant I which produce tires for the purpose of assembling and supply the needs of the production of motor vehicles on manufacturers in Indonesia and abroad. In order for the goods well organized, required inventory system which is expected to simplify the company in the process of inventory in a planned, controlled, systematic and be able to speed up the process of taking a decision. This study was conducted through direct observation, interviews, and collecting data in the form of a written document, print and electronic of agencies/institutions involved in this study. The results of the analysis will be used as inputs in the design of the proposed system applications. This system application design using the design of a system to describe the Use Case Diagram, Activity Diagrams, Class Diagrams; Prototype design consisting of a draft menu, draft Entry/Input Data and the draft reports. The results of the study which is done in well organized system is expected to control the process of an activity on the company, so as to reduce the occurrence of deviations and the work can be completed in time.
\end{abstract}


Keywords: Design, Application, Inventory System

\section{PENDAHULUAN}

Seiring dengan berjalannya waktu dan derasnya arus perkembangan teknologi, kebutuhan akan informasi juga semakin berkembang. Pada saat ini teknologi komputer telah berkembang sangat pesat dan telah menjadi kebutuhan utama dalam rangka meningkatkan kinerja suatu kegiatan didalam segala bidang. Kini teknologi tidak hanya sebagai pelengkap, tetapi sudah menjadi salah satu penentu atas terlaksananya sasaran dan strategi bisnis perusahaan. Teknologi yang canggih menimbulkan tantangan baru bagi perusahaan untuk menyediakan suatu sistem yang mampu mengintegrasikan kebutuhan informasi-informasi yang ada sehingga dapat mempermudah dan mempercepat perusahaan dalam pengambilan suatu keputusan.

Salah satu perusahaan yang tidak ingin tertinggal dalam memanfaatkan kemajuan teknologi ini adalah PT. Gajah tunggal, Tbk. Sebagai data awal, perusahaan ini menyediakan stock barang OEM (BAN) yang ditargetkan setiap harinya lebih kurang 75.263 pcs. untuk dalam tiga sift kerja dalam 24 jam. 45.000 pcs. untuk OEM dan 30.263 pcs. untuk OK, yang nantinya akan di kirim ke berbagai pabrikan sepeda motor di dalam dan luar negeri. Adapun size-size dan golongan ban tersebut antara lain adalah keterangan TL (tubbeleess) $M / C$ (tubetype) MC 90/90-17NR72 M/C, 90/90-17 NR72 T/L, 80/90-14 NR61 T/L, 90/90-14 NR62T/L, 90/100-17 RX01 T/L, 100/100-17 RX01R T/L, 110/90-17 RX01R T/L, 120/80-17 RX01R T/L, 130/70-17 RX01R T/L, 140/70-17 RX01R T/L, 160/70-17 RX01R T/L, ZN61 80/90-14 SS, ZN73 90/90-14 R, WildForce 275 100/70-17 R, WildForce 70/100-17 F, WF 60/80-17 SS dan masih banyak lagi size-size yang lain.

Banyaknya persediaan (stock) dan jenis barang di dalam gudang maka pencatatan stock barang menjadi sangat penting guna mengetahui jenis size-size apa saja yang sudah berlebih (overload) dan yang kurang persediaannya. Selain itu juga sangat diperlukan adanya sistem inventori yang baik, sehingga diharapkan perusahaan tersebut dapat mengontrol proses suatu kegiatan pada perusahaan, dapat mengurangi penyimpangan-penyimpangan yang terjadi dan pekerjaan dapat terselesaikan dengan tepat pada waktunya karena adanya sistem yang tersusun dengan rapi.

Penelitian ini dilakukan dengan menggunakan beberapa metode dalam pengumpulan data dan informasi, yaitu dengan metode observasi dan metode wawancara. Penulis melakukan pengamatan melibatkan semua indera (pengelihatan, pendengaran, penciuman, dan pencatatan secara teliti dan sistematis atas gejala-gejala (fenomena) yang sedang diteliti. Metode wawancara telah diakui sebagai teknik pengumpulan data atau informasi yang penting dan telah sering dilakukan dalam pengembangan sistem infromasi. Wawancara adalah suatu percakapan langsung dengan tujuan-tujuan tertentu dengan mengguanakan format tanya jawab yang telah direncana. Selanjutnya dengan menggunakan metode referensi yaitu suatu metode penelitian yang dilakukan dengan pengambilan data melalui dokumen tertulis, cetak maupun elektronik dari lembaga/institusi yang berkaitan dengan penelitian. Perancangan aplikasi sistem ini menggunakan Rancangan sistem untuk menggambarkan Use Case Diagram, Activity Diagram, Class Diagram; Rancangan Prototype yang terdiri dari Rancangan Menu, Rancangan Entry/Input Data dan Rancangan Laporan.

\section{PERMASALAHAN}

Setelah melakukan peneliatian pada sistem persediaan barang di gudang PT Gajah Tunggal Tbk. ternyata pembuatan beberapa laporan bukti serah terima barang dari deparment FI (final inspection) kepada department SBW (gudang) masih dilakukan secara manual sehingga dalam penyimpanan data masih kurang maksimal dan ini menyebabkan kinerja 
kurang maksimal, karena menyita tenaga dan waktu dalam melakukan pekerjaan. Data hasil laporan bukti serah terima barang dari department FI kepada department SBW hanya berupa arsip, sehingga tidak menjamin keamanan arsip yang disimpan. Banyaknya stock dan jenis barang (ban) didalam gudang PT. Gajah Tunggal Tbk. ini menjadi permasalahan, dimana perusahaan membutuhkan sistem inventory yang baik dan terkontrol.

Karena sistem persediaan barang di gudang PT Gajah Tunggal Tbk yang berjalan sekarang ini hanya menitik beratkan pada pendataan penerimaan barang dari bagian FI (final inspection). untuk itu diharapkan dapat membangun aplikasi penerimaan barang yang dilakukan secara terkomputerisasi agar proses dalam penrimaan barang dapat dilakukan dengan efisien tanpa harus menghabiskan banyak kertas dalam melakukan pendataan dan penerimaan barang dari bagian FI.

Berdasarkan penelitian sistem persediaan barang pada gudang PT Gajah Tunggal Tbk. memperlihatkan adanya beberapa masalah yang akan dikaji yaitu masalah kinerja sistem informasi pergudangan. Dalam hal ini bagaimana kinerja sistem informasi pergudangan di PT Gajah Tunggal Tbk yang sedang berjalan saat ini. Kemudian bagaimana tingkat efektifitas dan efesiensinya dari sistem informasi pergudangan atau stock barang gudang di PT Gajah Tunggal Tbk yang sedang berjalan saat ini. Permasalahan yang lebih penting lagi adalah bagaimana menganalisa rancang bangun aplikasi sistem informasi pergudangan atau stock barang gudang saat ini pada PT Gajah Tunggal Tbk.

\section{LANDASAN TEORI}

Pengertian sistem menurut Ludwig Von Bertalanfly dalam Yakub (2014:2)[1] "Sistem merupakan seperangkat unsure-unsur yang terkait dalam suatu antar relasi diantara unsureunsur tersebut dan dengan lingkunagannya". Sedangkan informasi didefinisikan oleh George H.B \& William, S.H. (2014:18)[2] "Informasi adalah data diolah sehingga dapat dijadikan dasar untuk mengambil keputusan"

Sedangkan Sistem Informasi Sutabri (2012:46)[3]: "Sistem Informasi adalah suatu sistem didalam suatu organisasi yang mempertemukan kebutuhan pengolahan transaksi harian yang mendukung fungsi operasi organisasi yang bersifat manajerial dengan kegiatan strategi dari suatu organisasi untuk dapat menyediakan kepada pihak luar tertentu dengan laporan-laporan yang diperlukan”.

Persediaan menurut Ikatan Akuntansi Indonesia (2004:14)[4] adalah sebagai berikut : "Persediaan adalah aktiva : a. Tersedianya untuk dijual dalam kegiatan usaha normal; $b$. Dalam proses produksi dan atau dalam perjalanan; $c$. Dalam bentuk bahan atau perlengkapan (supplier) untuk digunakan dalam proses produksi atau pemberian jasa." Pengertian persediaan menurut Soemarso S. R. (2004:384)[5] : "Persediaan adalah barangbarang yang dimiliki oleh perusahaan untuk dijual kembali." Persediaan terjadi apabila jumlah bahan atau barang yang diadakan (dibeli atau dibuat sendiri)." Menurut Warren et al (2004:440)[6] "Istilah persediaan dapat diartikan sebagai berikut : a. Barang dagang yang disimpan untuk dijual dalam opersional normal perusahaan; $b$. Bahan yang terdapat dalam proses produksi atau yang disimpan untuk tujuan perusahaan tersebut." Menurut (AgusRistono, 2013:7)[7] : "Pembagian jenis persediaan berdasarkan tujuannya, terdiri dari : 1. Persediaan pengamanan (safety stock); Persediaan antisipasi; 3. Persediaan dalam pengiriman (transit stock)."

\section{LITERATURE REVIEW}

Penelitian sebelumnya (literatur review) tentang penemuan-penemuan yang dilakukan oleh peneliti sebelumnya (emprical fiding) yang memiliki korelasi searah dengan penelitian ini sudah banyak dilakukan, diantaranya adalah: 
1. Penelitian yang di lakukan oleh Laela Fithriasari (2008)[8] berjudul "Perancangan Sistem Informasi Persediaan Barang Pada gudang Lokal PT. Indah Jaya Textile Industry" Permasalahan: Pada bagian persediaan barang yang meliputi pemesanan barang, stok barang, bon penyiapan barang, order barang serta laporan pemesanan barang, laporan stok barang, dan laporan order barang, masih dilakukan secara manual sehingga mengalami keterlambatan dalam hal pembuatan laporan persediaan barang, karena harus mencari arsip yang telah disimpan, akibatnya membutuhkan waktu yang relatif lama. Selain itu seringkali banyak data yang hilang. Penulis mengajukan perancangan sistem dengan menggunakan Visual Basic 6.0 untuk mempermudah proses pencatatan dan pembuatan laporan yang cepat, akurat dan efisien.

2. Penelitian yang dilakukan oleh Hadi Purnomo (2008)[9] berjudul "Aplikasi Inventory Gudang Obat Berbasis Web dan sms Gateway" Permasalahan: Petugas seringkali kesulitan dalam pengecekan stok obat atau arus pendisrtibusian obat. Solusi: perlu membuat suatu aplikasi inventory gudang obat berbasis Web untuk menunjang kinerja khususnya pada pendistribusian obat untuk memudahkan petugas mengecek stok obat atau arus pendisrtibusian obat sehingga dapat diminimalisir terjadinya kekurangan stok, dengan demikian kebutuhan obat untuk pasien akan selalu terpenuhi. Dalam aplikasi website tersebut, akan diperoleh informasi tentang stok obat yang ada dan jika stok obat menipis aplikasi akan otomatis mengirimkan sms ke pihak distributor obat menggunakan media sms gateway. Berdasarkan hasil uji coba,dapat diketahui bahwa sistem layak guna untuk dapat membantu menunjang kinerja petugas dalam memberikan informasi stok obat.

3. Penelitian yang dilakukan oleh Edi Eko Susilo (2009)[10] berjudul "Perancangan Sistem Informasi Data Warehouse Bagian Raw Material pada PT IRC Inoac Indonesia RGD". Permasalahan: Bagian Raw Material sewaktu menginput data dalam system laporan di PT. IRC Inoac Indonesia sering mengalami pengulangan pemakaian bahan pada lot yang sama dan banyaknya IP jenis produk yang belum terdapat katalog, tidak up to date-nya bahan setelah dipakai, akibatnya proses penginputan berjalan lama. Solusi yang diberikan yaitu perlu dibuatkan program agar bahan langsung berkurang pada waktu diambil tanpa menunggu proses konfirmasi dari atasan.

4. Penelitian yang dilakukan oleh Ulis Bella (2010)[11] berjudul "Perancangan Sistem Informasi Persediaan Barang Berbasis Web Pada Bagian Gudang Dinas" Permasalahan: Belum terkontrolnya barang yang masuk maupun keluar, karena sistem yang digunakan dalam pemasukan data masih menggunakan Ms. Excel dan belum dapat memberikan penyampaian informasi yang di butuhkan oleh stakeholder, karena sistem informasi yang berjalan saat ini belum memenuhi standar kepuasan, baik dari segi waktu, kualitas maupun dari segi laporan, karena laporan merupakan pendukung bagi manajemen dalam pengambilan keputusan. Dengan melihat situasi informasi persediaan alat tulis kantor pada Dinas Pendapatan Daerah saat ini, menjadikan sistem informasi tersebut belum efektif dalam melakukan proses pemasukan data. Solusi: perlu membuat suatu aplikasi perancangan sistem berbasis Web untuk menunjang kinerja pegawai di bagian gudang.

5. Penelitian yang dilakukan oleh Azizah Asri Kurniasari (2010)[12] berjudul "Aplikasi Sistem Inventori Gudang (ASIG) Berbasis Web" Pengolahan data inventori gudang di PT. Bandung Perdana Medikatama masih manual, yaitu pencatatan dan pengolahannya masih menggunakan selembar kertas berupa kartu persediaan. Pelaporan ke kantor pusat masih dilakukan dengan cara menyalin data inventori dari kartu tersebut kedalam Microsoft Office Excel. Setiap hari laporan dalam format Excel harus dikirim ke pihak kantor pusat via email, akibatnya pihak kantor pusat tidak dapat mengetahui data inventori masingmasing kantor cabang dengan cepat. PT. ini telah terhubung dengan jaringan Internet. Pemanfaatan Teknologi Informasi dapat dimaksimalkan dengan membangun aplikasi sistem inventori gudang berbasis web yang dapat diakses oleh pihak kantor pusat dan 
kantor cabang. Aplikasi dibangun dengan menggunakan waterfall model process, bahasa pemrograman PHP 5, dan database MySQL 5. Aplikasi ini dapat digunakan pihak PT. ini terutama petugas bagian gudang dalam menginventarisasi produk yang ada di gudang. Inventarisasi ini meliputi pencatatan, pengolahan, penyimpanan, dan pelaporan data inventori gudang. Pihak kantor pusat dapat melihat pelaporan dari kantor cabang dari Web dan sekaligus dapat mengetahui data inventori masing-masing kantor cabang dengan cepat, tepat, dan akurat.

6. Penelitian yang dilakukan oleh Kokok Budy Antonno (2010)[13] berjudul" Perancangan Sistim Informasi Inventory Gudang Berbasis Internet". PT. Duta Mas. Permasalahan: Inventory produk masih dilakukan secara manual sehingga bagian penjualan tidak mengetahui jumlah persedian produk di dalam gudang karena tidak adanya akses informasi yang terhubung. Solusi: untuk mengetahui stock produk khususnya produk jadi maka dibutuhkan Sistem Informasi Inventory Gudang (SIGA) berbasis Intranet. Karena pengaturan inventory yang baik harus selalu dapat menjawab pertanyaan berapa jumlah produk yang ada dalam gudang dan kapan produk tersebut dibutuhkan. Implementasi ini menggunakan bahasa scripting yang terpasang pada HTML sehingga memungkinkan pengecekan dan pengawasan secara langsung melalui system jaringan komputer. SIGA dibangun dengan perangkat lunak open source yang menggunakan bahasa pemograman PHP dan manajemen basis data MySQL, serta menggunakan komputer server berbasis Windows.

Dari pengembangan penelitian ini dengan enam (6) referensi para peneliti sistem yang dapat dibandingkan dan dilihat hasil dari pengembangan sistem-sistem yang pernah diteliti sebelumnya dapat disimpulkan bahwa: Hasil penelitian yang dilakukan oleh Laela Fithriasari (2008) adalah sebuah aplikasi menggunakan Visual Basic 6.0 dan Databasenya SQL Server 2000, kelemahan sistem ini masih banyak terjadi keslahan dalam penginputan data; Hasil penelitian yang dilakukan oleh Hadi Purnomo (2008) adalah sebuah aplikasi berbasis web dan dengan menggunakan sms Gateway, kelemahan dalam sistem ini sering terjadi ke tidak akuratan stock barang antara input barang di web dengan menggunakan sms gateway; Hasil penelitian yang dilakukan oleh Edi Eko Susilo (2009) adalah sebuah aplikasi menggunakan Visual Basic 6.0 dan Database SQL Server 2000, kelemahan sistem yang dikembangkan belum dapat berjalan secara optimal, karena masih menggunakan Visual Basic 6.0; Hasil penelitian yang dilakukan oleh Ulis Bella (2010) adalah sebuah aplikasi menggunakan Program Web. Kelemahan sistem yang dikembangkan masih banyak terjadi kesalahan dalam pengimputan data; Hasil penelitian yang dilakukan oleh Azizah Asri Kurniasari (2010) adalah sebuah aplikasi Pemrograman berbasis Web. Kelemahan: dalam aplikasi ini belum dapat menampilkan data User name dan password; Hasil penelitian yang dilakukan oleh Kokok Budy Antonno (2010) adalah menggunakan aplikasi berbasis internet. Kelemahan sistem yang dikembangkan belum update-nya data perencanaan dan pengendalian secara menyeluruh.

\section{ANALISA DAN PEMBAHASAN}

Pada analisa sistem yang berjalan, bagian gudang di PT. Gajah Tunggal, Tbk. sudah memilik aplikasi sistem informasi yang di program untuk membantu atau mempermudah dalam melakukan kegiatan kerja, yang meliputi : (1) Input data barang; (2) Barang keluar; (3) Cetak hasil input data barang; dan (4) Laporan hasil penerimaan barang.

Sebelum dikembangkan sistem terlihat bahwa beberapa masalah yang ditemui sebelum memiliki aplikasi informasi persediaan barang pada gudang yaitu terdapat kesulitan dalam proses pencarian barang karena pendataan barang masih dilakukan secara manual. Dilihat dari segi efisiensi waktu sangat tidak menguntungkan karena menghabiskan banyak waktu 
dalam memberikan hasil laporan. Apabila dilihat dari segi efisiensi ruangan yaitu menghabiskan banyak tempat dalam penyimpanan hasil laporan pendataan barang.

Sistem yang berjalan terbagi dalam proses-proses yang ada dalam sistem informasi pergudangan yaitu dapat digambarkan sebagai berikut :

1. Prosess Login

Admin harus melakukan proses login terlebih dahulu kedalam aplikasi persediaan barang pada gudang.

2. Proses Input Data Barang

a. Admin melakukam pengecekan laporan data barang sebelum di input apabila masih terdapat kekurangan, maka admin akan mengembalikan hasil laporan kepada bagian FI (final inspection).

b. Admin menginput data hasil laporan yang telah diterima dari bagian FI (final inspection).

3. Cetak Hasil Input Barang.

Admin mencetak hasil laporan penerimaan barang yang telah diserahkan oleh bagian FI (final inspection) kemudian diserahkan ke bagian administrasi untuk dijadikan laporan bulanan.

4. Barang Keluar.

Bagian pejualan (marketing) memberikan surat permintaan barang dengan menyerahkan PO (purchase order) dari customer. Bagian gudang akan mengecek persediaan, jka persediaan barang ada maka dibuatkan surat jalan dan barang akan dikirim ke customer.

5. Laporan Penerimaan Barang

Setiap bulannya pada bagian administrasi akan mencetak laporan hasil penerimaan barang dari bagian FI (final inspection) kebagian gudang untuk diserahkan kepada pimpinan bagian gudang sebagai laporan bulanan. Dan juga pada bagian administrasi memeriksa semua data laporan yang ada disistem, data yang ditampilkan akan di cetak dan diserahkan kepada Asisten Department Head.

Dilihat dari fungsi dan kegunaan sistem dapat dijelaskan sebagai berikut :

a. Fungsi Sistem

Terdapat tiga fungsi sistem informasi persediaan barang pada gudang yaitu sebagai :

1. Basis data pergudangan

Sebagai tempat penyimpanan data catatan gudang yang di pergunakan untuk kegiatankegiatan gudang.

2. Informasi data gudang

Dapat menampilkan informasi-informasi yang di butuhkan seperti data penerimaan barang yang paling banyak diterima.

3. Laporan gudang

Data-data yang ada pada sistem persediaan barang pada gudang di cetak guna untuk menjadi laporan.

b. Kegunaan Sistem

Adapun kegunaan sistem persediaan barang pada gudang adalah :

1. Mempermudah dalam proses pendataan laporan kegiatan seperti laporan penerimaan barang.

2. Mempermudah dalam proses pencarian data.

\section{Penggambaran Sistem}

a. Use Case Diagram

Di bawah ini dapat dijelaskan melalui gambar usecase bagaimana proses user (admin/FI) menggunakan system mulai dari proses input sampai output. Dapat dilihat pada gambar di bawah ini : 


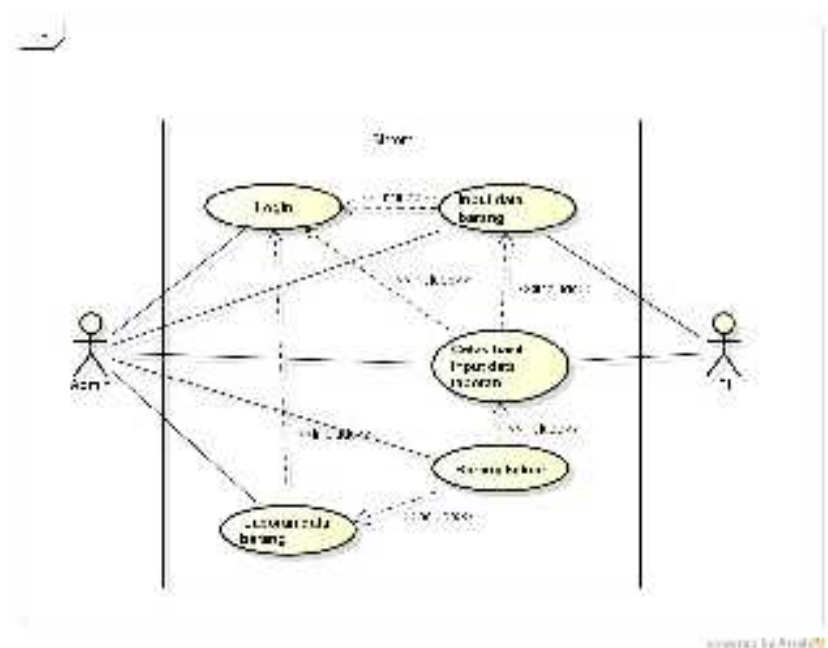

Gambar 1 Use Case diagram

\section{Sequence Diagram}

\section{Sequence diagram login}

Di bawah ini dapat dilihat melalui gambar sequence diagram bagaimana interaksi proses antar objek didalam system yang berjalan mulai dari pengguna, display dan proses login.

Dapat di lihat pada gambar di bawah ini :

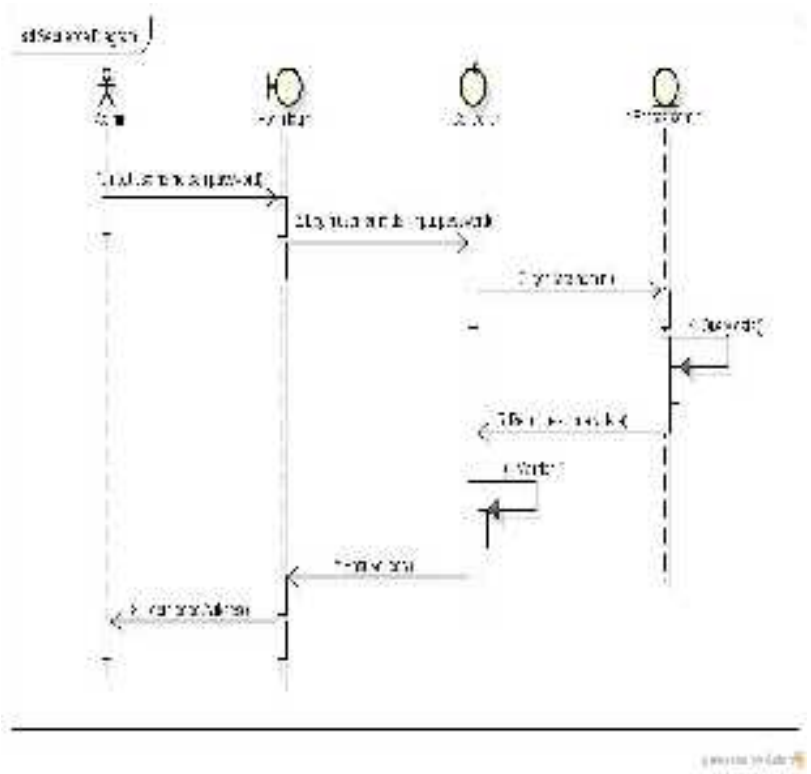

Gambar 2 Sequence Diagram Login Admin

\section{Sequence input data barang}

Pada gambar sequence input data barang dibawah ini dijelaskan bagaimana objek melakukan prosedur input data barang pada system. Dapat dilihat pada gambar di bawah ini : 


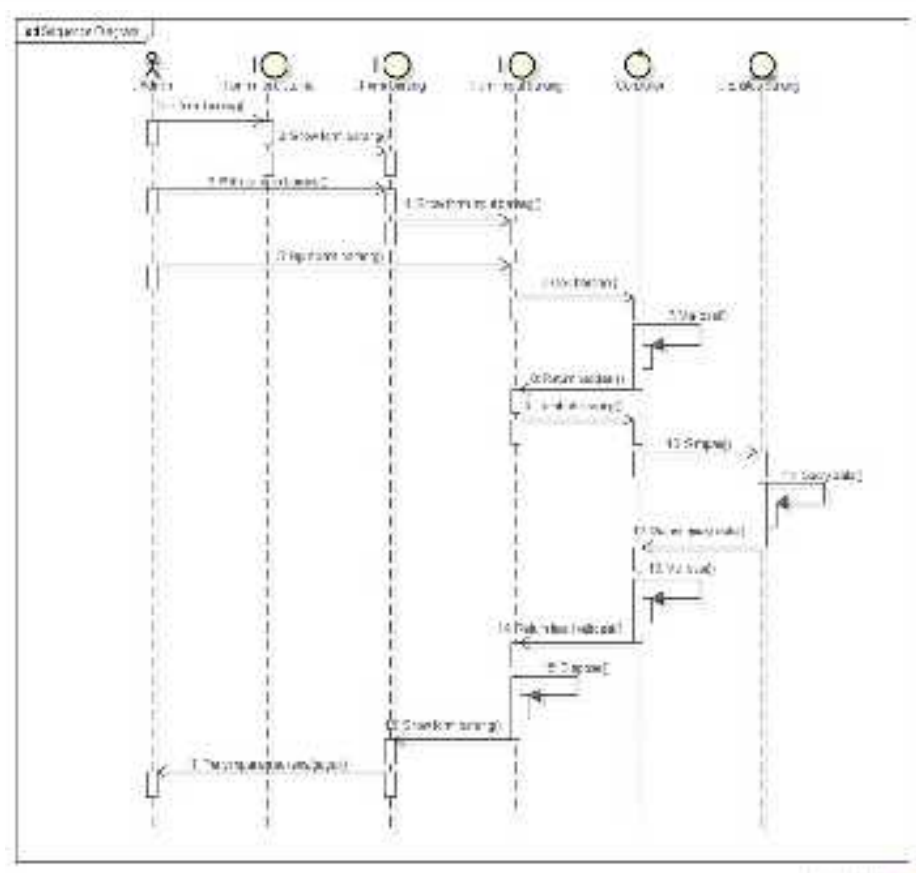

Gambar 3 Sequence Diagram Input data barang

\section{Sequence barang keluar}

Dalam gambar sequence barang keluar dibawah ini dapat dilihat bagaimana proses objek untuk melakukan pendataan barang yang keluar melalui system. Dapat dilihat pada gambar di bawah ini :

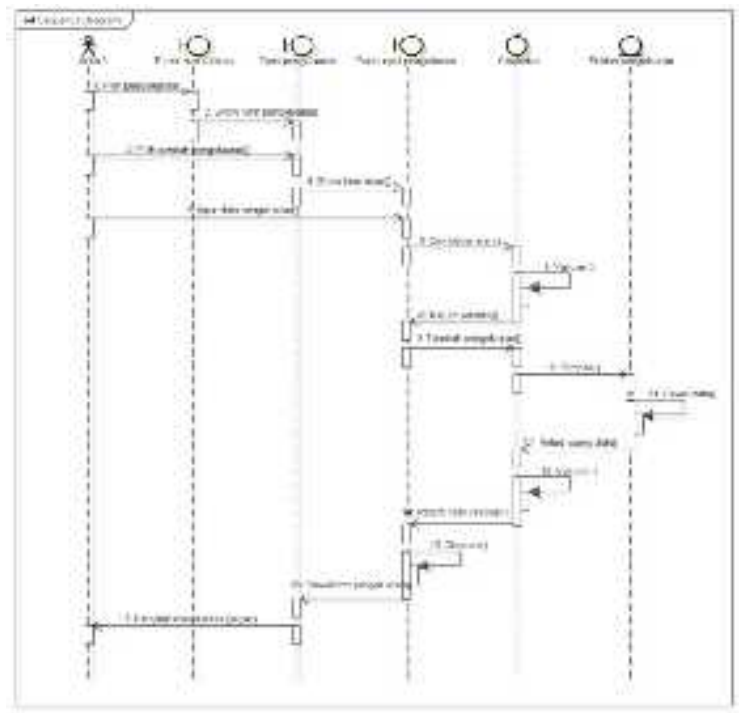

\section{Gambar 4 Sequence Diagram barang keluar}

\section{Sequence laporan}

Bagaimana proses user / admin melakukan kegiatan dalam mendapat laporan sesuai prosedur di dalam system dapat dilihat dalam gambar sequence laporan di bawah ini : 


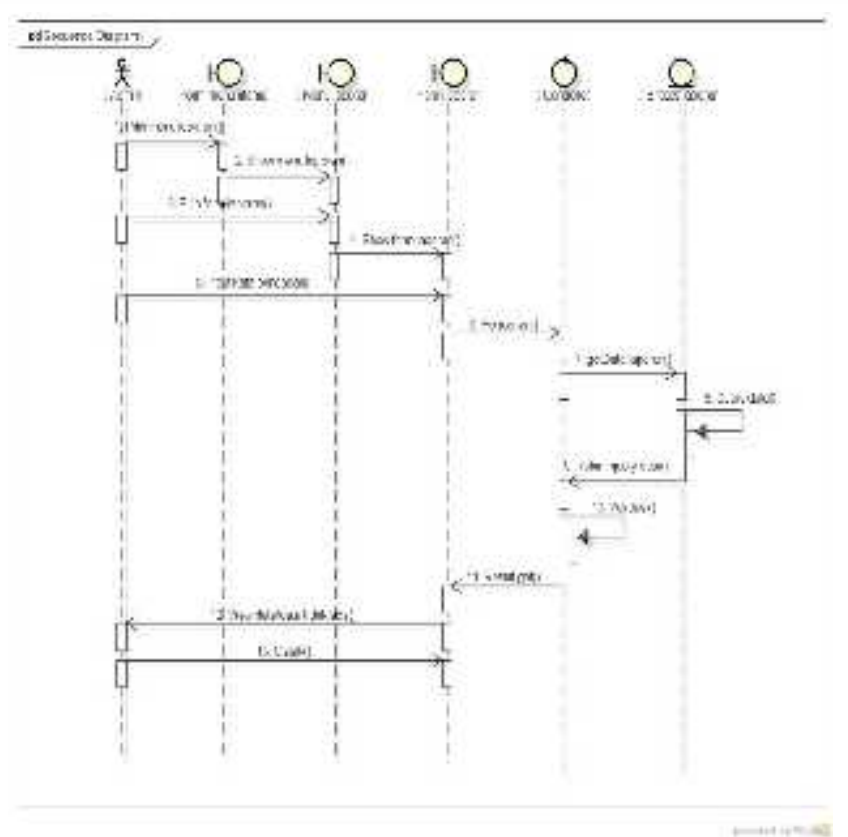

Gambar 5 Sequence laporan

\section{Statechart Diagram}

\section{Statechrat diagram login}

Dalam gambar dibawah ini dijelaskan bagaimana transisi program dalam mengakses system untuk proses login system. Dapat di lihat pada gambar di bawah ini :

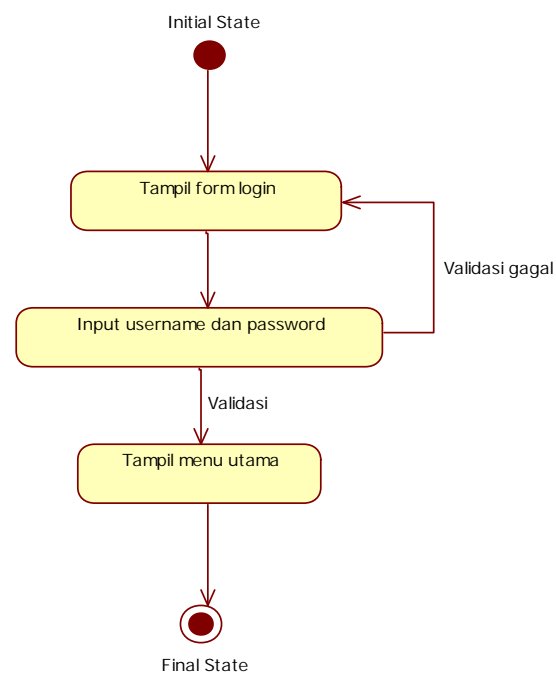

Gambar 6 Statechart Diagram login

\section{Statechart diagram input data barang}

Dapat dilihat dalam gambar statechart diagram input data barang di bawah ini. Bagaimana proses transisi dalam system untuk meng input data-data barang yang akan diproses. Lihat gambar di bawah ini : 


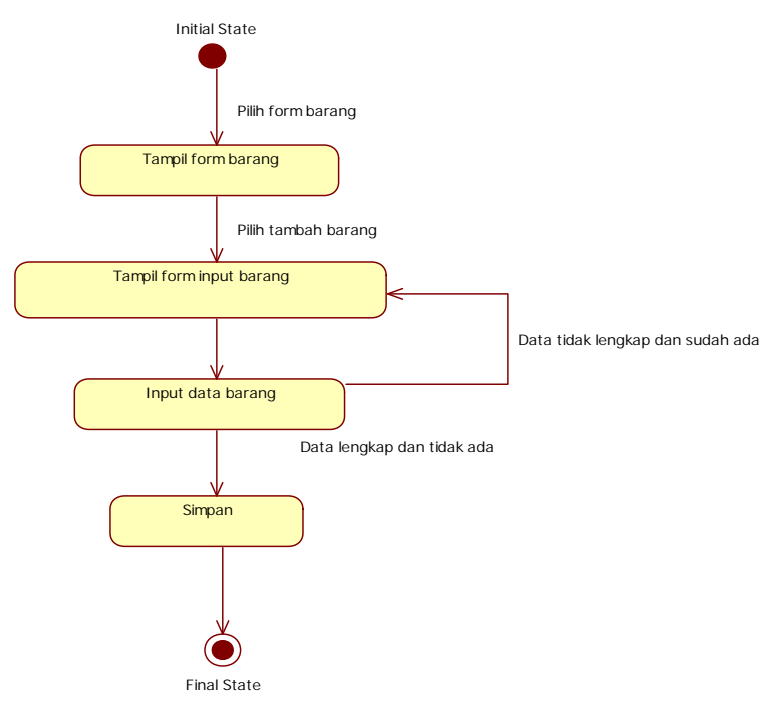

Gambar 7 Statechart Diagram Input data barang

\section{Statechart diagram barang keluar}

Untuk lebih jelas bagaimana transisi proses user/admin melakukan olah data untuk laporan barang keluar dapat dilihat pada gambar statechart diagram di bawah ini :

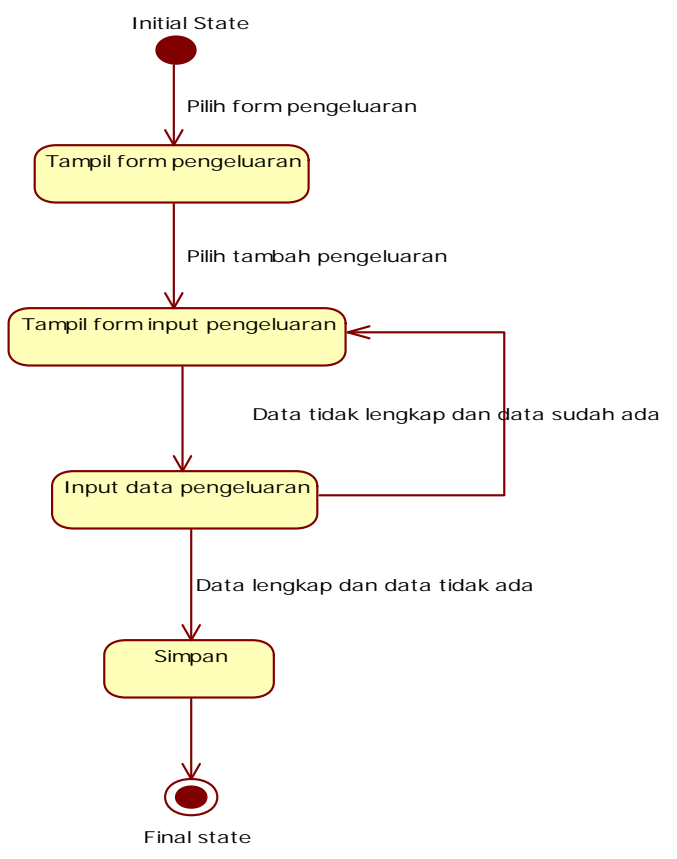

\section{Gambar 8 Statechart Diagram barang keluar}

\section{Statechart laporan}

Bisa dilihat dalam gambar statechart laporan di bawah ini. Bagaimana proses transisi untuk memproses hasil dari data-data laporan yang akan di cetak. Lihat gambar di bawah ini : 


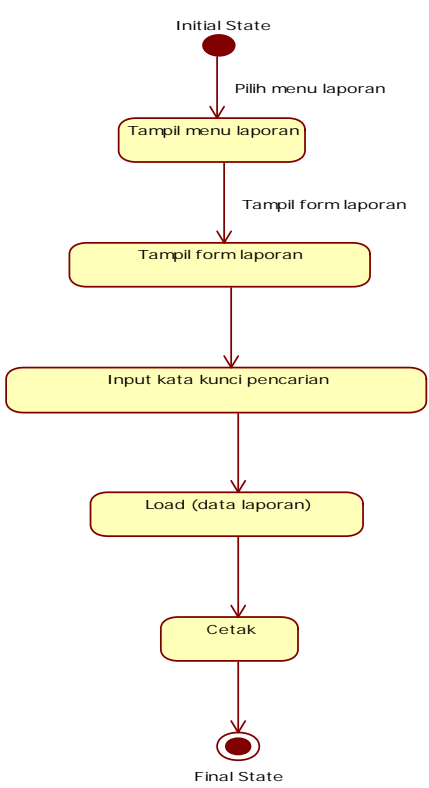

Gambar 9 Statechart laporan

\section{Activity Diagram}

Activity diagram di gunakan untuk menggambarkan kegiatan-kegiatan yang ada di dalam suatu sistem. Berikut ini activity diagram sistem yang berjalan :

\section{Activity diagram login admin}

Dapat dilihat pada gambar activity diagram login di bawah ini . bagaimana aliran kerja (worlflow) system untuk admin melakukan login pada system.

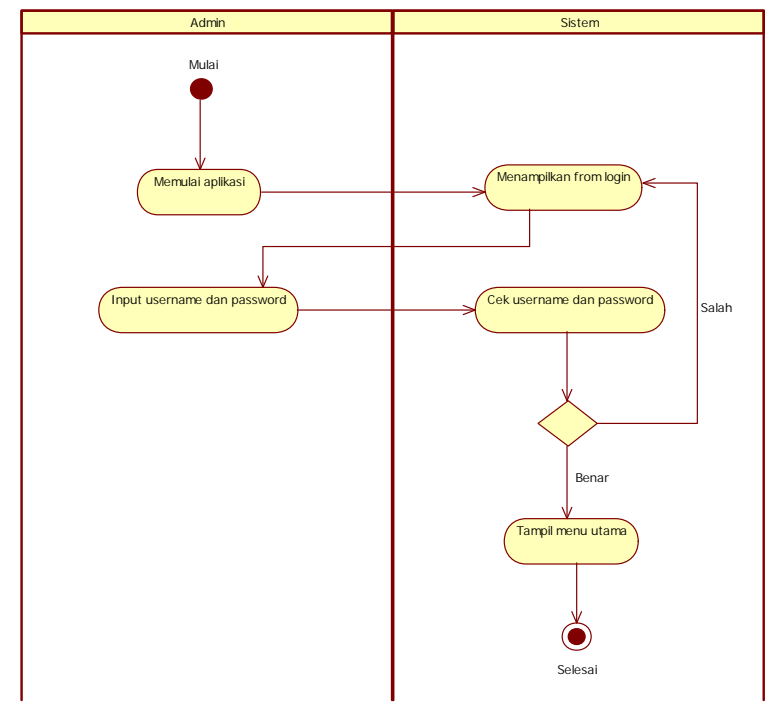

Gambar 10 Activity Diagram Login admin

\section{Activity diagram input barang}

Dapat dilihat pada gambar activity diagram input barang di bawah ini . bagaimana aliran kerja (worlflow) system setelah melakukan login kemudian melakukan input barang pada system. 


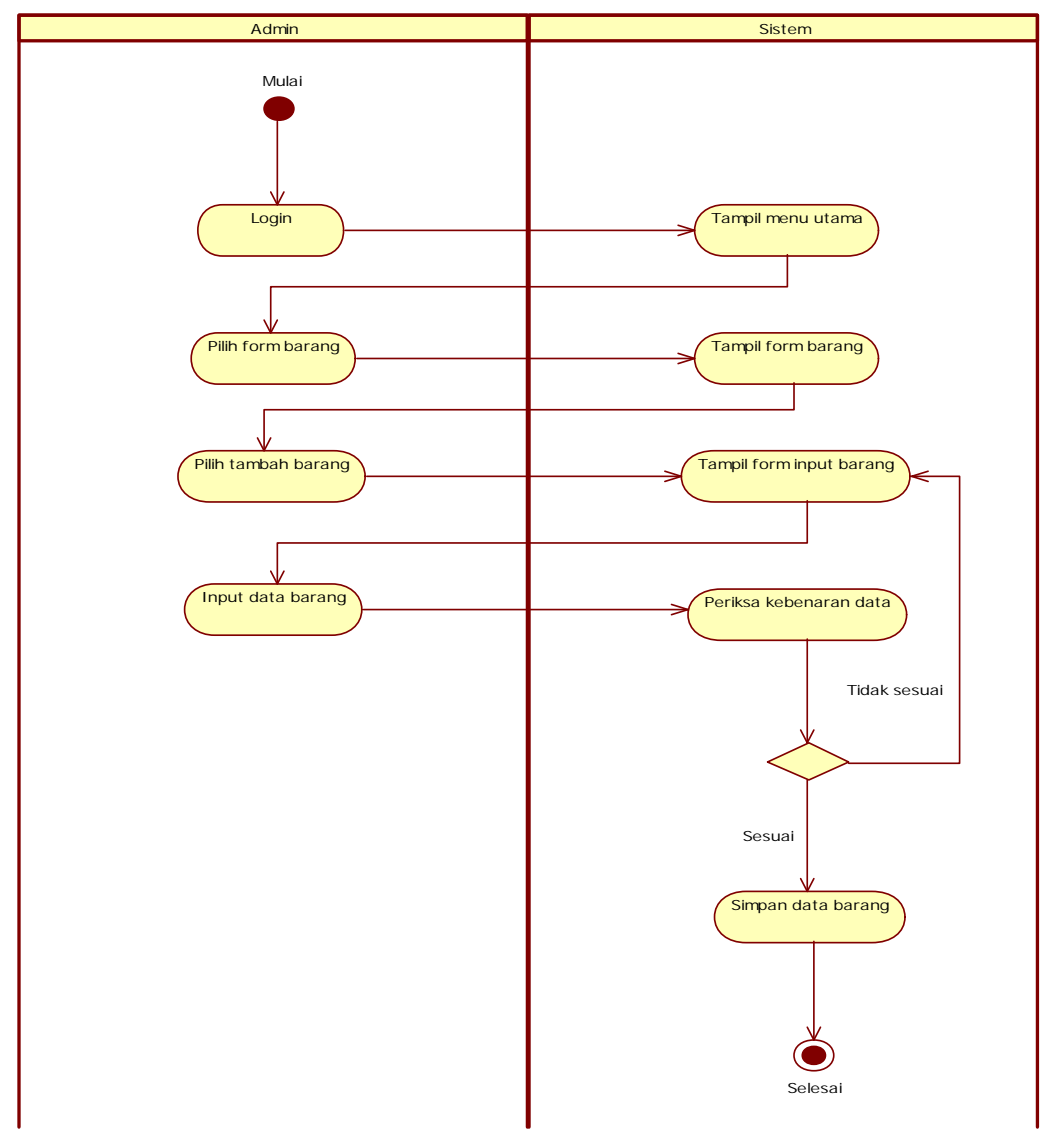

Gambar 11 Activity Diagram Input barang

\section{Activity diagram barang keluar}

Dapat dilihat pada gambar activity diagram barang keluar di bawah ini . bagaimana aliran kerja (worlflow) system setelah melakukan login, input data, dan kemudian pengolahan data barang keluar pada system. 


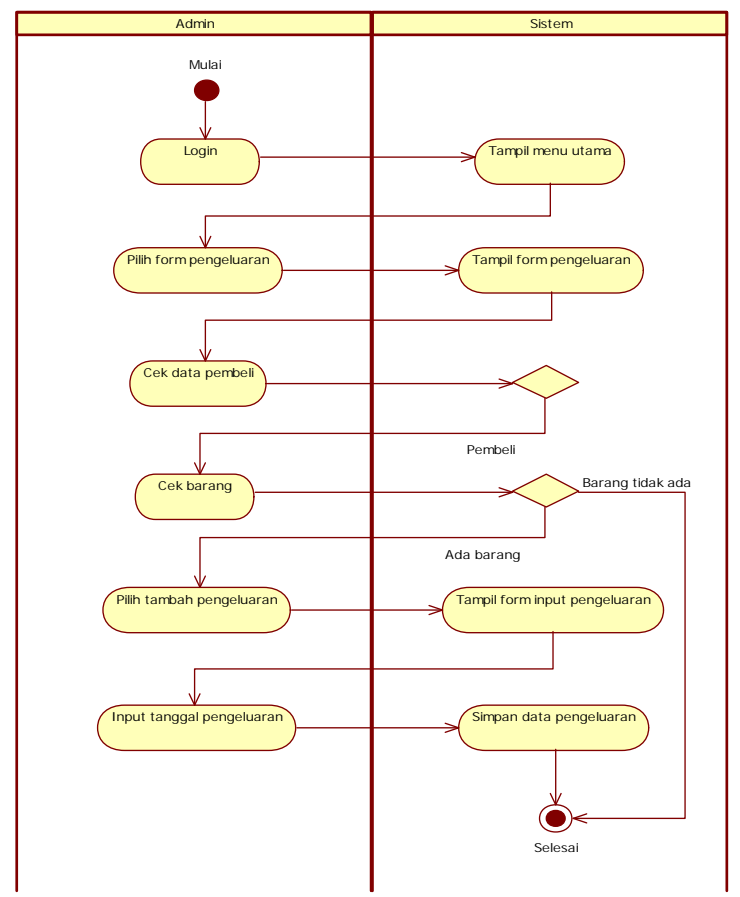

Gambar 12 Activity Diagram barang keluar

\section{Activity diagram laporan}

Dapat dilihat pada gambar activity diagram laporan di bawah ini . bagaimana aliran kerja (worlflow) system untuk admin melakukan cetak laporan pada system

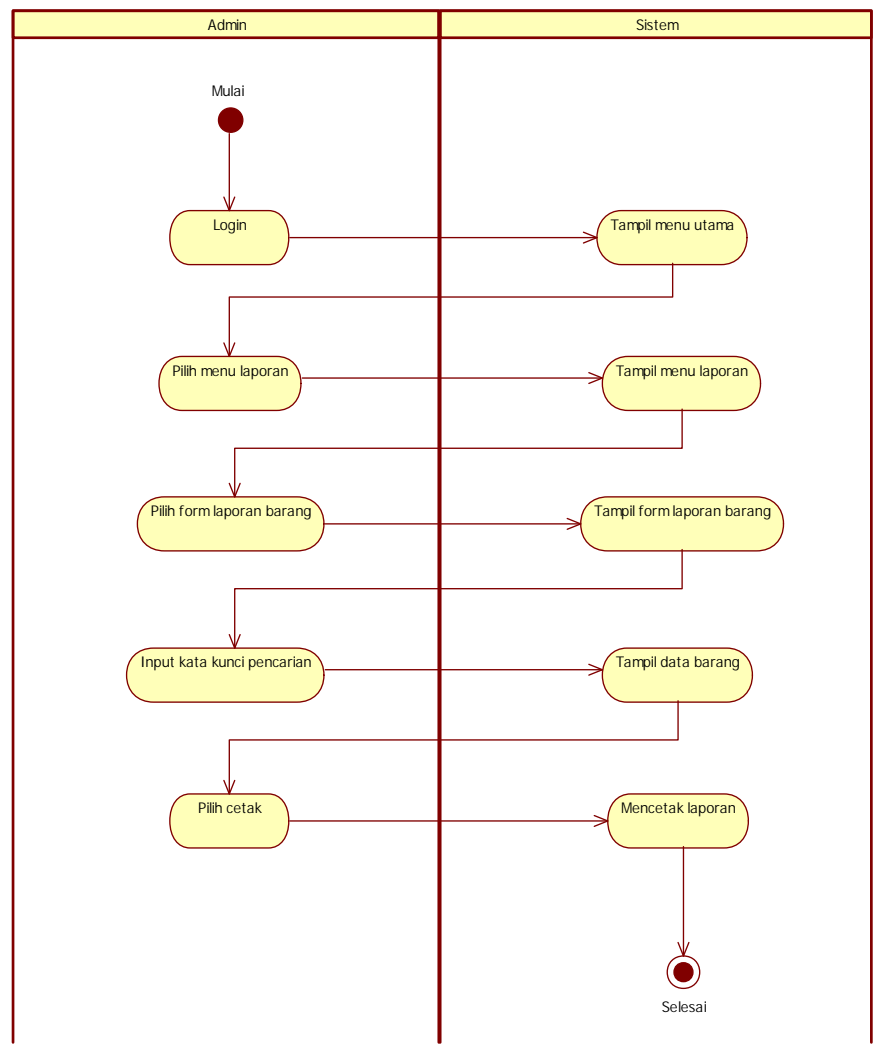

Gambar 13 Activity Diagram laporan 


\section{Class diagram}

Dalam gambar class diagram dibawah ini dapat di lihat bagaimana setiap kelas-kelas dalam system ada sebuah relasi dari system satu ke system yang lain. mulai dari pegawai sampai barang. Lihat gambar di bawah ini :

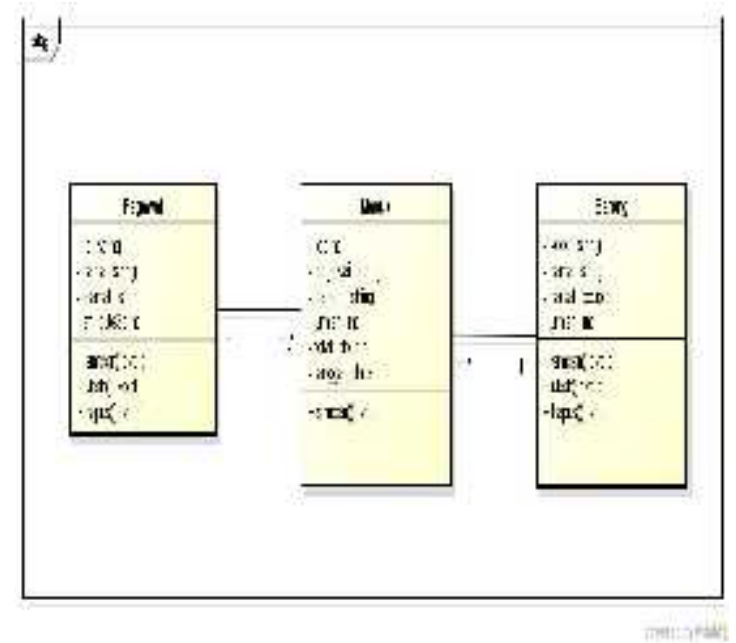

Gambar 14 Class Diagram

\section{Hardware dan Software}

\section{Hardware}

1. Monitor : ACER LED 18.5 inch

2. Keyboard dan mouse logitech

3. Printer dot matrix EPSON LX 300 dan printer EPSON L550

4. Processor : Intel core i3 CPU @ 2.20GHz (4 CPUs) $2.2 \mathrm{GHz}$

5. RAM : $2.0 \mathrm{~GB}$

\section{Software}

1. Windows 7 Profesional 32 bit (6.1 build 7601).

2. JAVA SE (standart edition) bahasa pemrogramman java untuk aplikasi desktop.

3. ORACLE di gunakan untuk basis data.

\section{Kelebihan dan Kekurangan Sistem}

Kelebihan Sistem:

1. Mudah di pelajari dalam hal penggunaannya.

2. Mempermudah dan meminimalkan waktu proses pengolahan data gudang.

3. Mampu menghasilkan informasi yang berupa laporan data barang.

4. Tampilannya sangat menarik.

Kekurangan Sistem:

Pencarian informasi barang hanya dilakukan dalam satu komputer saja, sehingga menimbulkan antrian dan memperlambat dalam pencarian barang yang masih tersedia dan sudah tidak tersedia.

\section{KESIMPULAN}

Berdasarkan uraian dari prosess analisa maka dapat disimpulkan sebagai berikut :

1. Kinerja sistem informasi pergudangan di PT Gajah Tunggal Tbk yang sedang berjalan saat ini masih kurang maksimal karena sistem persediaan barang dan pembuatan beberapa 
laporan bukti serah terima barang dari deparment FI (final inspection) kepada department SBW (gudang) masih dilakukan secara manual sehingga dalam penyimpanan data masih kurang tertata dengan baik, sehingga mengakibatkan kinerja kurang maksimal dan menyita tenaga dan waktu dalam melakukan pekerjaan.

2. Sistem informasi pergudangan atau stock barang gudang di PT Gajah Tunggal Tbk yang sedang berjalan saat ini menunjukkan sangat tidak efektif dan tidak efisien. Ini terbukti dengan cara manual pihak gudang tidak mendapatkan informasi mengenai data manajemen barang secara lebih mudah dan lebih cepat.

3. Penganalisaan rancang bangun aplikasi sistem informasi pergudangan atau stock barang gudang saat ini pada PT Gajah Tunggal Tbk adalah sebagai berikut: Sistem persediaan barang yang tertata dengan baik pada gudang dapat membantu pegawai gudang dalam mempermudah pendataan barang; Sistem ini dapat digunakan sebagai alat bantu meningkatkan kinerja pegawai gudang dan mempermudah dalam penyajian data persediaan barang; Sistem ini dapat menyimpan data gudang yang meliputi tipe ban dan penerimaan barang dari bagian FI (final inspection) yang tidak memerlukan ruang dan media fisik yang terlalu besar; Dengan adanya sistem persediaan barang ini juga dapat menghasilkan data-data proses pengolahan menggunakan komputerisasi dengan hasil lebih akurat dan tingkat kesalahan kecil dibandingkan dengan sistem yang dilakukan secara manual sebelumnya; Dengan adanya sistem persediaan barang ini pihak gudang akan dapat mendapatkan informasi mengenai data manajemen barang secara lebih mudah dan lebih cepat.

\section{DAFTAR PUSTAKA}

[1] Yakub. (2012). Pengntar Sistem Informasi. Yogyakarta: Graha Ilmu

[2] George H.B \& William, S.H. (2014) Sistem Informasi Manajemen. Yogyakarta: Graha Ilmu

[3] Sutabri, Tata. (2012). Konsep Sistem Informasi. Yogyakarta: Andi.

[4] Ikatan Akuntansi Indonesia (2004). Standar Akuntansi Keuangan.

[5] Soemarso. SR. (2004). Akuntansi Suatu Pengantar, Buku 1, Edisi ke-6. Jakarta: PT.Rimeka Cipta.

[6] Warren. Reeves, Fees (2004). Pengantar Akuntansi. Jakarta. Salemba Empat.

[7] Ristono, Agus. (2013). Manajemen Persediaan. Yogyakarta: Graha ilmu.

[8] Laela Fithriasari (2008) [7] "Perancangan Sistem Informasi Persediaan Barang Pada gudang Lokal PT. Indah Jaya Textile Industry”, Tangerang, STMIK Raharja.

[9] Hadi Purnomo (2008) "Aplikasi Inventory Gudang Obat Berbasis Web dan sms Gateway" Tangerang. STMIK Raharja.

[10] Edi Eko Susilo (2009) "Perancangan Sistem Informasi Data Warehouse Bagian Raw Material pada PT IRC Inoac Indonesia RGD". Tangerang, STMIK Raharja.

[11] Ulis Bella (2010) "Perancangan Sistem Informasi Persediaan Barang Berbasis Web Pada Bagian Gudang Dinas” Tangerang, STMIK Raharja.

[12] Azizah Asri Kurniasari (2010) "Aplikasi Sistem Inventori Gudang (ASIG) Berbasis Web” Tangerang, STMIK Raharja.

[13] Kokok Budy Antonno (2010) "Perancangan Sistim Informasi Inventory Gudang Berbasis Internet”. Tangerang, STMIK Raharja.

[14] Pengertian analisa menurut para ahli http://pengertianbahasa.blogspot.com/2013/02/pengertian-analisis.html, akses 28 juli 2014

[15] Penjelasan persediaan http://dansite.wordpress.com/2009/03/31/pengertianpersediaan-inventoryl, akses 29 juli 2014 
[16] Penjelasan UML (Unified Modeling Language)

http://bayuaji.staff.gunadarma.ac.id/Downloads/files/32096/UML.pdf,akses 1 agustus 2014

[17] Pengantar UML (Unified Modeling Language)

http://202.154.59.182/mfile/files/Tubagus\%20Purworusmiadi/Kumpulan\%20File\%20PD F/MateriSuplemenUml-2.pdf, akses 5 agustus 2014

[18] Yuni Sugiarti. (2013). Analisis dan Perancangan UML (Unified Modeling Language). Penerbit Graha Ilmu

[19] Anhar (2010). Panduan Menguasai PHP Dan MySQL Secara Otodidak, mediakita, Jakarta, 2010. 